1 Fundação Oswaldo Cruz (Fiocruz), Escola Nacional de Saúde Pública Sérgio Arouca (Ensp) - Rio de Janeiro (RJ), Brasil. aguiar.luciene@gmail.com

2 Fundação Oswaldo Cruz (Fiocruz), Escola Nacional de Saúde Pública Sérgio Arouca (Ensp) - Rio de Janeiro (RJ), Brasil. elfadel@globo.com

\section{A gestão do Sistema Único de Saúde e a Saúde do Trabalhador: o direito que se tem e o direito que se perde}

\author{
The management of the Unified Health System and the Worker's \\ Health: the right we have and the right we lost
}

Luciene Aguiar', Luiz Carlos Fadel de Vasconcellos ${ }^{2}$

RESUMO Inscritas na Constituição Federal de 1988, as ações de Saúde do Trabalhador no Sistema Único de Saúde carecem de uma efetividade capaz de mudar os alarmantes indicadores epidemiológicos de acidentes e doenças do trabalho. Mesmo sendo reflexo da postura político-econômica dos governos pós-constitucionais, a gestão do Sistema Único de Saúde é determinante na omissão e, mesmo, ofensa ao que se estabelece constitucionalmente. O texto, de caráter ensaístico, baseou-se em dados atualizados da Previdência Social, e em documentos e artigos sobre o campo da Saúde do Trabalhador e da hermenêutica jurídica quanto à aplicabilidade das normas que regem as ações, especialmente de saúde pública, do Poder Executivo no Estado de Direito.

PALAVRAS-CHAVE Saúde do Trabalhador; Acidentes de trabalho; Gestão em saúde; Sistema Único de Saúde; Constituição.

ABSTRACT Enrolled in the Federal Constitution of 1988, the worker's health actions within the Unified Health System require effectiveness able to change the alarming epidemiological indicators of accidents and work-related diseases. Even being reflection of the political-economic posture of post-constitutional governments, Unified Health System is decisive in the omission and, likewise, in the offense to what is established constitutionally. This text, of essayistic character, was based on updated data from the Social Security, and on documents and articles about the worker's health field and legal hermeneutics regarding to the applicability of the rules that govern the actions, especially of public health, of the executive power in the Law's State.

KEYWORDS Occupational health; Accidents, occupational; Health Management; Unified Health System; Constitution. 


\section{Perplexidade diante dos dados}

É comum se ouvir dizer que há leis que 'pegam' e leis que 'não pegam'. Em matéria de atenção à Saúde do Trabalhador (ST), podemos dizer que a lei 'não pegou'. Embora a Constituição Federal de 1988 (CF/88) seja clara, direta e objetiva no que tange às atribuições do Sistema Único de Saúde (SUS) quanto à ST, no decorrer de sua implementação, a disposição normativa e operacional evidenciou certa indolência com a saúde dos trabalhadores, a ponto de causar perplexidade, se olharmos para os dados epidemiológicos de acidentes e doenças relacionadas ao trabalho.

Mesmo tendo a ST sido normatizada em alguns aspectos, ao longo dos últimos 25 anos pós-SUS, a forma como o foi, e tem sido, mostra uma intenção operativa irrelevante no sentido de mudar o cenário epidemiológico brasileiro.

A situação dos agravos relacionados ao trabalho é um dos pontos de partida para o estranhamento frente à irrelevância da área de ST, enquanto parte substantiva, como deveria ser, das políticas públicas de saúde no Brasil. Observamos adiante um breve panorama dos dados epidemiológicos disponíveis.

As estatísticas oficiais de acidentes e doenças relacionadas ao trabalho, no Brasil, são estabelecidas desde o final da década de 1960 pela Previdência Social, por intermédio da Comunicação de Acidente de Trabalho (CAT), que consiste em um sistema de coleta de informações para efeito de processamento de benefícios. Sua vocação epidemiológica, capaz de desencadear ações de vigilância da saúde, é nula. Apenas tangencialmente ele é capaz de taxar empresas por majoração de ônus sobre o seguro acidente de trabalho, no caso de aumento na incidência de agravos evidenciados por acompanhamento de séries históricas dos setores produtivos. Este sistema, que existe há quase 50 anos, não dialoga com os sistemas de informação em saúde. Mesmo porque, só recentemente, o SUS principiou a inclusão, em seu rol de agravos de notificação compulsória, alguns relacionados ao trabalho. E, mesmo assim, o nível de notificação é baixíssimo, se comparado ao sistema CAT, ainda que, ao contrário deste, todos os trabalhadores brasileiros sejam alvo de notificação perante o SUS.

Como se sabe, o sistema previdenciário é exclusivo para trabalhadores regidos pela Consolidação das Leis do Trabalho (CLT), inclusive, com algumas exceções, como é o caso dos empregados domésticos, que não participam das estatísticas. Ainda assim, o número de acidentes de trabalho (inclusive, doenças), com milhões de trabalhadores fora desse ranking (servidores públicos dos quatro entes federativos, militares de toda ordem, autônomos, cooperativados e prestadores de serviços, entre inúmeros outros), alcançou a casa dos 40 milhões, desde que se iniciou o seu registro.

Em 2013, o Instituto Nacional de Seguridade Social (INSS) registrou 717,9 mil acidentes de trabalho. Comparando-se com 2012, o número aumentou em 0,55\%. $\mathrm{O}$ total de acidentes registrados com a CAT aumentou em 2,3\%, de 2012 para 2013. Dos acidentes registrados com a CAT, os chamados acidentes típicos (aqueles ligados diretamente à atividade do trabalho) responderam por $77,32 \%$; os acidentes de trajeto representaram 19,96\%; e as doenças do trabalho contribuíram com $2,72 \%$. Os homens participaram com $73,01 \%$ e as mulheres com $26,99 \%$ nos acidentes típicos; no caso dos acidentes de trajeto, respectivamente, $62,21 \%$ e $37,79 \%$; e nas doenças do trabalho, $58,38 \%$ e $41,62 \%$. A faixa etária de maior incidência foi constituída por jovens de 20 a 29 anos, no caso dos acidentes típicos e de trajeto. Nesta faixa etária, os homens participaram com $34,11 \%$ e as mulheres com $37,50 \%$ do total de acidentes registrados em seu agrupamento, por sexo. As doenças relacionadas ao trabalho incidiram majoritariamente na faixa de 30 
a 39 anos, representando $33,52 \%$ do total de acidentes registrados em todas as faixas etárias (BRASIL, 2015A).

Em relação aos óbitos, os números são aterradores. O Anuário Estatístico da Previdência Social de 2011 registra 82.171 óbitos por acidentes de trabalho, entre 1988 e 2011 (BRASIL, 2011A). Sabemos que esta estatística é subestimada, especialmente porque grande parte dos acidentes de trânsito é relacionada ao trabalho e não é computada como tal. Os acidentes com mototaxistas são reflexos desta realidade:

Diversos estudos, no Brasil, apresentam o comportamento e as características dos acidentes com motocicletas no trânsito, porém, poucos conseguem apresentar uma relação explícita entre esse tipo de acidente com o acidente de trabalho. (DUARTE, 2011, P. 28).

Além disso, o mesmo anuário registra 363.107 incapacidades permanentes para o trabalho, no período. Igualmente subestimados, os números refletem essa realidade assustadora, em que centenas de milhares de trabalhadores foram retirados compulsoriamente do mercado de trabalho, em virtude da forma como se organizam os processos produtivos no Brasil.

O que faz com que um gravíssimo problema de saúde pública seja tratado normativamente, ora de forma inexpressiva e mesmo ausente, ora de maneira insuficiente para engendrar análises e intervenções capazes de interromper este panorama inconcebível? E sempre com um alinhamento periférico e marginal a outros problemas de saúde pública que, embora sejam igualmente relevantes, não ostentam a magnitude dramática desses indicadores.

\section{A regra constitucional - omissão e ofensa}

Antes de analisarmos as possíveis razões para o destrato com a questão, é preciso refletir sobre o significado do instrumento normativo, enquanto peça operativa da execução de regras no Estado de direito. Situar a norma infraconstitucional na sua vocação de fazer valer a regra constitucional é o que se espera nos atos operativos do sistema de saúde.

O novo direito constitucional brasileiro, cujo desenvolvimento coincide com o processo de redemocratização e reconstitucionalização do País, foi fruto de duas mudanças de paradigma: a) a busca da efetividade das normas constitucionais, fundada na premissa da força normativa da Constituição; b) o desenvolvimento de uma dogmática da interpretação constitucional, baseada em novos métodos hermenêuticos e na sistematização de princípios específicos de interpretação constitucional. A ascensão política e científica do direito constitucional brasileiro conduziu-o ao centro do sistema jurídico, onde desempenha uma função de filtragem constitucional de todo o direito infraconstitucional, significando a interpretação e leitura de seus institutos à luz da Constituição. (BARROSO, 2001, P. 47).

É curioso que, a despeito da volúpia normativa que existe no Brasil e, muito fortemente, no SUS, são patentes a baixa frequência da ST nas normas existentes e uma escassez de normas específicas que tratam das relações saúde-trabalho.

A propósito do excesso de normatização no Brasil, o fenômeno da hiperlegislação é documentado por números extravagantes. Segundo o Instituto Brasileiro de Planejamento e Tributação, entre 05 de outubro de 1988 (data da promulgação da Constituição Federal) e 31 de agosto de 2013, foram editadas 4.785.194 normas que regulam as relações sociais no País, os direitos e deveres dos cidadãos. A média totaliza 784 normas editadas por dia útil. No nível federal foram editadas 158.663 normas, no estadual foram 1.219.569 normas e no âmbito municipal foram 3.406.962 (AMARAL; OLENIKE; AMARAL, 2013). 
A área da saúde comparece com força de liderança: "Saúde, Educação, Segurança, Trabalho, Salário e Tributação são temas que aparecem em $45 \%$ de toda a legislação" (AMARAL; OLENIKE; AMARAL, 2013, P. 2).

$\mathrm{E}$, mesmo tendo o tema saúde, assim como o tema trabalho, participado majoritariamente do conjunto de toda a legislação, quando se trata de normatizar sobre a ST, revela-se sua escassez.

De qualquer modo, esse fenômeno inflacionário de normas indica-nos cautela em qualquer intenção propositiva de fazer alguma coisa pela área de ST. Não se trata, portanto, de concorrer com a reivindicação de novas normas que venham a tratar da ST, embora elas até possam ser necessárias em determinadas circunstâncias, mas impõe-se analisar o porquê de, nas normas já editadas, a expressão da área de ST se mostrar incapaz de impulsionar a tomada de decisão para ações concretas capazes de reverter os alarmantes números.

Em relação àquela fúria legiferante, Souza $(2012$, P. 5) adverte:

[...] a ausência de parâmetros e paradigmas mais precisos abre a possibilidade para que as leis se validem tão-somente pela adequação formal em relação ao ordenamento jurídico. Assim, no que pertine ao conteúdo material, este somente é legitimado se a lei for formalmente adequada.

Uma das inquietudes que norteiam este trabalho é justo esta: será que a questão da ST é adequada ao sistema de saúde, a ponto de ser legitimada em seu conteúdo material? Dobrowolski (1999, P. 253) indaga se a norma legal no Estado contemporâneo é "[...] um plano de ação destinado a modificar a ordem social existente ou serve apenas para resolver um problema concreto".

Mirando a CF/88, com base nesta reflexão, é necessário recorrer à intenção normativa constitucional.

A inscrição da ST no espírito constituinte pretendia modificar a ordem social que regulara até então as questões relacionadas ao mundo do trabalho na sua estreita ligação com a saúde. Parece-nos que esta foi a resposta constitucional, em tempos de reforma radical do sistema de saúde, ao fato de que o aparelho de Estado da saúde pública esteve alheio durante décadas aos problemas da relação saúde-trabalho. Vinculada às normas de caráter contratualista, e não universalista, das áreas estatais do trabalho e da previdência social, a Saúde do Trabalhador pré-constitucional não era um problema de saúde (VASCONCELLOS, 2007).

Quanto ao problema concreto referido por Dobrowolski (1999), entendemos que os dados epidemiológicos antes demonstrados, que, já à época do processo constituinte ostentavam essa magnitude, impulsionaram o espírito reformista de então, corroborando o interesse do legislador em transformar a questão da saúde dos trabalhadores em um problema concreto de saúde pública e colocá-lo no âmbito do direito de todos e dever do Estado.

Se a Reforma Sanitária trouxe em seu ideário o espírito de subordinação aos princípios de justiça e inclusão social (FLEURY, 2009), é no estatuto da norma constitucional que essa capacidade poderá ser desenvolvida, a partir de suas normas operativas no mundo dos fatos.

É bem verdade que uma norma que antecede as normas subsequentes, que lhes dão corporeidade no mundo real, muitas vezes, na conjuntura político-econômica, perde sua força original. Parece ser esse o caso da ST. Assim, a intenção de fazer justiça perde seu elo com a regra do direito. Cabe perguntar: Que direito se tem e que direito se perdeu, se está perdendo e ainda se perderá?

Deve existir uma razão final, uma norma fundamental, que é a fonte da validade de todas as normas que pertencem a certa ordem jurídica. Embora a existência de toda norma seja condicionada por certo fato, não é um fato, mas uma norma, o motivo pelo qual todas as 
normas do sistema existem - isto é, são válidas. Isso demonstra claramente que uma norma não é idêntica a seu fato condicionador. (KELSEN, 2001, P. 213).

Essa contradição entre o que diz a norma geradora, maior, e o que ocorre na vida real, não é novidade em matéria das relações saúde-trabalho. Marx, no Livro 1, tomo 2, de O Capital, ao falar "[d]o estado de saúde dos trabalhadores" (MARX, 1988, P. 95), recorre ao relato do Dr. Simon, funcionário do Privy Council e editor dos Public Health Reports:

Em meu quarto relatório', mostrei como é praticamente impossível para os trabalhadores sustentar o que seria seu primeiro direito em matéria de saúde, o direito de que, qualquer que seja a atividade para a qual seu empregador os reúna, o trabalho deva estar livre de todas as circunstâncias nocivas à saúde que possam ser evitadas, na medida em que isso dependa dele. Demonstrei que, enquanto os trabalhadores forem praticamente incapazes de alcançar por si mesmos essa justiça sanitária, não poderão conseguir nenhuma ajuda eficaz dos administradores nomeados da polícia sanitária. [...] A vida de miríades de trabaIhadores e trabalhadoras é, agora, inutilmente torturada e encurtada pelo sofrimento físico sem fim, causado apenas por sua ocupação. (MARX, 1988, P. 95).

O texto de um século e meio atrás mantém sua atualidade quando assinala a incapacidade dos trabalhadores de alcançarem uma justiça sanitária, por si mesmos, aliada à omissão dos órgãos oficiais responsáveis pela polícia sanitária. Dois aspectos ressaltam-se aqui:

$1^{\mathrm{o}}$ - Embora o controle social do SUS deva garantir aos trabalhadores um protagonismo na confecção das normativas que lhes façam alcançar uma justiça sanitária, isto $2^{\mathrm{o}}$ - Continuamos sob uma ordem omissa dos órgãos oficiais de vigilância da saúde (responsáveis pela polícia sanitária).

Ainda nesse 'salto epistemológico' de 150 anos, chegamos a 1999, 11 anos depois de promulgada a Constituição Federal de 1988. Naquele ano, a Organização Pan-Americana da Saúde deu início a um projeto de avaliação da gestão em saúde pública, denominado de Funções Essenciais da Saúde Pública (Fesp). Seu objetivo foi o de fortalecer as autoridades sanitárias nas Américas.

O uso das Fesp oferece aos países uma excelente oportunidade para renovar os conceitos da saúde pública e refletir sobre as práticas institucionais. Uma saúde pública entendida como responsabilidade do Estado e da sociedade civil interessada numa saúde individual e coletiva que garanta o acesso equitativo a serviços públicos e privados com qualidade e com uso racional dos recursos humanos e tecnológicos. Um exercício renovado da saúde pública que utilize o monitoramento, a análise e avaliação da situação da saúde das populações como instrumento de políticas de saúde para a organização de serviços individuais e para a vigilância, investigação e controle de riscos e danos em saúde pública. Uma saúde pública responsável, que interaja com os cidadãos e com a sociedade, para garantir transparência no uso dos recursos sociais mediante mecanismos de arrecadação de contas e participação cidadã. (FINKELMAN, 2002, P. 299).

Foram consideradas 11 Fesp: (1) Monitoramento e análise da situação da saúde; (2) Vigilância e investigação de riscos em saúde pública; (3) Promoção da saúde; (4) Participação social dos cidadãos; (5) Desenvolvimento de políticas e capacidade institucional de planificação e gestão em saúde; (6) Fortalecimento da capacidade institucional de regulação e fiscalização; (7) Avaliação e promoção do acesso equitativo em saúde; (8) Desenvolvimento de recursos humanos e capacitação; (9) Garantia de qualidade dos 
serviços de saúde individual e coletiva; (10) Investigação em saúde pública; e (11) Redução do impacto de emergências e desastres.

No Brasil, esse instrumento de avaliação foi aplicado a 65 gestores de saúde, nas três esferas de governo. Considerando os diversos tipos de instâncias, os gestores elegeram quatro Fesp mais relevantes para o desenvolvimento institucional sob sua responsabilidade: a $\mathrm{n}^{\mathrm{o}} 6$ (fortalecimento da capacidade institucional de regulação e fiscalização); a $\mathrm{n}^{0} 1$ (monitoramento e análise da situação da saúde); a $\mathrm{n}^{0} 7$ (avaliação e promoção do acesso equitativo em saúde); e a n ${ }^{\circ} 10$ (investigação em saúde pública) (FINKELMAN, 2002).

Embora a abordagem das relações saúde-trabalho exija uma capacidade de desenvolvimento institucional baseado nas 11 Fesp para o seu enfrentamento, o arcabouço normativo da ST, cuja construção obedeceu às suas peculiaridades teórico-conceituais, identifica-se de forma preponderante com as Fesp $\mathrm{n}^{\circ} 2$ (vigilância e investigação de riscos em saúde pública) e $n^{\circ} 4$ (participação social dos cidadãos), que foram citadas de modo inexpressivo pelos gestores brasileiros.

Em 2007, o Conselho Nacional de Secretários de Saúde (Conass) publicou um relatório sobre as Fesp adaptadas ao Brasil, e não houve mudança na ênfase assinalada pela gestão à época (CONASS, 2007).

Além de apontar a 'não' priorização do enfrentamento das questões que envolvem as relações saúde-trabalho, calcadas nas normativas operacionais e nas pactuações da gestão do SUS, é também necessário compreender o 'espírito' da gestão, quando estabelece o planejamento das ações que envolvem o tema.

Nas tentativas correntes de um planejamento social na forma jurídica, admite-se implicitamente um entendimento historicamente novo do direito, do tempo e do planejamento, que devemos tomar consciente para que ele possa ser referido enquanto base do planejamento. (LUHMANN, 1985, P. 166).
$\mathrm{Ou}$, em outras palavras, que conveniências ou inconveniências movem o espírito público do gestor a fazer escolhas do que deve ou não ser pactuado e planejado, e em que medida, muitas vezes ofendendo o preceito constitucional explícito.

Em sua função, ao gestor público cabe observar aquilo que deve ser cumprido e, obviamente, cumprir.

A administração pública reveste-se do princípio da indisponibilidade do interesse público, segundo o qual, o administrador, em todas suas condutas, deve levar em conta aquilo que atende ao interesse da coletividade. (SCHMITZ, 2013, P. 2).

No caso do SUS, o interesse da coletividade é estabelecido por inúmeros parâmetros, dos quais se destaca o perfil epidemiológico dos agravos, e, tanto as normas operacionais quanto os planos de ação pactuam-se entre os próprios gestores nos mecanismos estabelecidos na lei, por meio das comissões intergestoras (BRASIL, 2011B). Entretanto, muitas vezes predominam outros interesses, por parte dos gestores, que não os da coletividade, especialmente em determinados temas, caso da ST. Ao serem retirados da esfera de preocupação dos gestores, os problemas decorrentes da relação saúde-trabalho são também retirados da agenda de prioridades do sistema de saúde.

Se é taxativa a determinação constitucional para realizar ações e serviços de ST, seria de se esperar um outro nível de preocupação da gestão com o tema. Nesse caso, alinhamo-nos com Schmitz (2013, P. 23):

[...] quando o administrador público deixa de atender alguma política pública prevista constitucionalmente, ele estará ferindo o ordenamento jurídico, além de tentar esvaziar aquilo que o constituinte julgou como imprescindível.

Spagolla e Morete (2011, P. 20) seguem a mesma linha ao proporem a constitucionalização do Direito Administrativo, e argumentam: 
Ora, a fim de orientar todo o ordenamento jurídico do Estado, tanto para sua integração quanto para a elaboração de novas normas, o constituinte - traduzindo os anseios da sociedade na oportunidade da criação da Constituição Federal - estabeleceu princípios norteadores da ação de seus agentes. Arrolou, especificamente, princípios referentes à Administração Pública [...].

A propósito dessa questão, recente decisão (2011) do Ministro Celso de Mello, do Supremo Tribunal Federal, é elucidativa:

O Poder Público - quando se abstém de cumprir, total ou parcialmente, o dever de implementar políticas públicas definidas no próprio texto constitucional - transgride, com esse comportamento negativo, a própria integridade da Lei Fundamental, estimulando, no âmbito do Estado, o preocupante fenômeno da erosão da consciência constitucional.

[...] É que nada se revela mais nocivo, perigoso e ilegítimo do que elaborar uma Constituição, sem a vontade de fazê-la cumprir integralmente, ou, então, de apenas executá-la com o propósito subalterno de torná-la aplicável somente nos pontos que se mostrarem ajustados à conveniência e aos desígnios dos governantes, em detrimento dos interesses maiores dos cidadãos. (BRASIL, 2011C).

\section{Saúde do Trabalhador - a regra e os fatos}

Em 1992, aos dois anos de vigência da Lei Orgânica da Saúde (Lei no 8.080, de 19 de setembro de 1990), Oliveira e Vasconcellos já destacavam o caráter marginal e periférico que o campo assumia, em matéria de interesse da saúde pública.

É pertinente ressaltar o caráter de marginalidade da área de Saúde do Trabalhador, pois mesmo as instituições responsáveis pelas ações apresentam um interesse secundário pela questão. [...] O processo de absorção das ações da saúde do trabalhador, por parte do SUS, vem apresentando diversos problemas e, até o momento, não podemos afirmar que as mesmas estejam sendo executadas eficazmente. [...] De um lado, a marginalidade de que se reveste a questão da Saúde do Trabalhador no contexto do setor saúde. De outro, a fragmentação de atribuições e responsabilidades na área (OLIVEIRA; VASCONCELLOS, 1992, P. 153).

No caso da sua institucionalidade, as políticas de ST que vêm sendo implementadas exibem problemas de viabilidade executiva, em virtude de sua baixa capacidade de se fixar nos serviços de saúde pública em geral. Desde o início de sua implantação como campo de ações do SUS, legitimadas pela Lei $\mathrm{n}^{\circ} 8.080 / 90$, a área se institucionalizou de forma voluntarista e errática, por intermédio dos chamados Programas de Saúde do Trabalhador (DIAS, 1994). Mesmo com a criação da Rede Nacional de Atenção Integral à Saúde do Trabalhador (Renast), em 2002, instituída pela Portaria $\mathrm{n}^{\circ} 1.679$, de 19 de setembro, cujo objetivo era integrar, fortalecer, organizar e sistematizar as ações de ST no SUS, não podemos dizer que a área esteja instituída de modo eficaz e eficiente (LEÃO; VASCONCELLOS, 2011). Sua proposta de implementar ações assistenciais, de vigilância e de promoção à ST no âmbito do SUS, com foco nas relações trabalho-saúde-doença, tendo os Centros de Referência em Saúde do Trabalhador (Cerest) como um lócus privilegiado de suporte técnico para essas ações, bem como de organizar e sistematizar informações e ter um papel facilitador da capacitação para o controle social, tanto técnicos quanto profissionais do SUS ainda apresentam dificuldades para sua efetivação. Dias e Hoefel enumeram algumas dificuldades a serem superadas: 
a) a lógica do modelo da Renast, centrada na atuação regionalizada dos CRSTs, não corresponde à organização do SUS centrada na municipalização; b) frágil articulação intra-setorial uma vez que a Saúde do Trabalhador ainda não foi efetivamente incorporada na Agenda de Saúde do SUS, nos níveis federal, estadual e municipal; c) confusão dos papéis das coordenações estaduais e municipais de Saúde do Trabalhador e dos Centros de Referência; d) falta de orientação clara quanto aos processos de pactuação dos procedimentos de assistência, vigilância e informação em saúde, uma vez que, com freqüência, as áreas de atuação dos CRSTs não coincidem com as Regionais de Saúde; e) o despreparo dos profissionais de saúde que atuam na rede de serviços para lidar com os riscos e agravos à saúde, relacionados com o trabalho e definir os encaminhamentos médicos e administrativos adequados; f) o controle social [...] fragilizado [...]; g) desvio dos recursos destinados à implantação da Renast para cobrir outras necessidades no âmbito do sistema de saúde; h) [...] precedência da assistência em detrimento das ações de vigilância, prejudicando a integralidade das ações; i) as ações intersetoriais ainda são tímidas e localizadas. (DIAS; HOEFEL, 2005, P. 825-826).

Ao se observar, mesmo que de forma sucinta, a irrelevância do campo de ST nos instrumentos normativos, fica evidente que estes fazem raras menções ao campo e, quando o fazem, é na linha de notificação de agravos, sem estabelecer metas de ações que interrompam os fatores determinantes desses mesmos agravos. Um exemplo marcante é o que está estabelecido no documento pactuado pela Comissão Intergestores Tripartite, 'Orientações acerca dos indicadores da pactuação de diretrizes, objetivos e metas 2012'.

Diretriz 7 - Redução dos riscos e agravos à saúde da população, por meio das ações de promoção e vigilância em saúde [...] Objetivo
Nacional 7.1 - Fortalecer a promoção e vigilância em saúde [...] Indicador 24 - Proporção de municípios que notificam doenças/agravos relacionados ao trabalho da população residente Meta Brasil:

\begin{tabular}{|c|c|}
\hline \multirow[t]{2}{*}{ Indicador } & Meta Brasil \\
\hline & 2012 \\
\hline $\begin{array}{c}\text { Proporção de } \\
\text { municípios } \\
\text { que notificam } \\
\text { doenças/agravos } \\
\text { relacionados } \\
\text { ao trabalho da } \\
\text { população resi- } \\
\text { dente. }\end{array}$ & $\begin{array}{l}\text { Ampliar o número de municípios } \\
\text { com serviço de notificação de } \\
\text { doenças/agravos relacionados } \\
\text { ao trabalho da população resi- } \\
\text { dente. } \\
\text { Meta: } 75 \% \text { dos municípios, com } \\
\text { pelo menos uma unidade de } \\
\text { saúde, com serviço de notifica- } \\
\text { ção de doenças/agravos relacio- } \\
\text { nados ao trabalho implantado. }\end{array}$ \\
\hline
\end{tabular}

Esfera de pactuação: Federal, Estadual e DF. Descrição do indicador: Identifica, entre os municípios brasileiros, a existência de notificação de pelo menos 1 dos 11 agravos relacionados ao trabalho constantes da Portaria $\mathrm{n}$ 은 104/2011. (BRASIL, 2015B).

Ora, ao quadro epidemiológico de proporções dramáticas, anteriormente apresentado, sobrepõe-se uma pactuação das três esferas de governo no sentido de notificar (apenas) um entre 11 agravos, como meta de ST no Brasil, sem apontar metas para a redução dos agravos notificados.

É evidente que muitas das iniciativas no tocante à realização de ações e serviços de ST, no âmbito do SUS, representaram avanços para a consolidação da área. A própria criação da Renast, embora trouxesse a marca de um

[...] vício original de foco assistencialista, trouxe inegáveis avanços para o campo da Saúde do Trabalhador [...] a ampliação dos centros pelo País; a capacidade de possuir dotação orçamentária própria; desdobramentos na sua condução como a elaboração de protocolos de agravos e procedimentos; o estímulo 
ao intercâmbio entre os centros; o desencadeamento de processos de capacitação; e, entre outros, a manutenção de um status permanente de mobilização de seus componentes. (VASCONCELLOS, 2007, P. 256).

Contudo, esses avanços foram insuficientes para trazer mudanças no panorama sanitário, inclusive, sendo muitas vezes seguidos por retrocessos na condução das práticas.

Desvendar que pontos se ajustam 'à conveniência e aos desígnios dos governantes' em matéria de 'não' enfrentar a ST com a força que o problema exige é um desafio esperando a sua hora de ser enfrentado.

\section{Uma síntese reflexiva}

Por certo, são muitas as razões que levam os gestores do SUS a se omitirem e mesmo ofenderem a Constituição Federal neste tópico. $\mathrm{O}$ fato de haver uma multiplicidade de órgãos estatais responsáveis pela ST, sem uma sintonia fina entre eles, é uma delas. $\mathrm{O}$ enfrentamento, especialmente no nível local, com os setores econômico-produtivos, criando desconfortos entre a gestão pública e os financiadores das campanhas eleitorais, é outra delas. Considerando que as ações de vigilância são a essência da capacidade transformadora da ST, especialmente no nível local, é factível vislumbrar os entraves para o seu desenvolvimento a contento, por contrariar interesses econômicos, em virtude da

[...] dificuldade apresentada pela própria característica do campo da Saúde do TrabaIhador, que o coloca no meio de uma relação complexa entre o capital e o trabalho. Se por um lado, essa característica aproxima do campo atores envolvidos e ligados através do componente ideológico e do agir político, por outro lado, distancia as questões de saúde dos assuntos prioritários, em virtude de lidar com questões que mexem com interesses econômicos e, por isso, são alvo de pressões políticas para que se mantenha o status quo. (ALMEIDA, 2012, P. 49).

O poder político expresso nos parlamentos das esferas federal, estadual e municipal, cujo interesse mal tangencia a defesa das relações saúde-trabalho, é outra razão. Uma análise mais acurada depende de um aprofundamento que extravasa o propósito deste texto.

Em síntese, podemos assinalar:

- Existe uma inflação normativa no Brasil, com grande participação da esfera da saúde pública;

- Mesmo hiperinflacionada, a normatização em saúde não dá mostras de intencionar resolver o 'problema da Saúde do Trabalhador';

- Os trabalhadores não têm oportunidades de alcançar uma justiça sanitária, por si mesmos;

- Existe uma omissão da gestão pública em relação a alguns temas, de acordo com a sua conveniência, onde se inclui, nesse rol de omissões, a saúde dos trabalhadores;

- Existe um descompasso entre o que determina a Constituição Federal de 1988 e o que a gestão do SUS operacionaliza.

García-Villegas (2013), reportando-se especialmente à América Latina, observa que, em países onde os direitos sociais são ainda precários, as constituições são aspiracionais (constitucionalismo aspiracional, no original), ou seja, aspiram a transformações sociais em contextos conservadores e bloqueadores das mudanças. Enunciando o paradoxo, o autor se indaga se essas constituições são textos jurídicos ou simplesmente enunciados políticos. Assim se manifesta:

Las constituciones aspiracionales se caracterizan por mantener una profunda distancia respecto de las realidades sociales y políticas que quieren transformar. Esta ruptura está inscrita en su naturaleza futurista y progresista. La constitución no 
expresa el país que existe sino el que queremos. (GARCÍA-VILLEGAS, 2013, P. 96).

Esta aguda observação aplica-se com propriedade à área de Saúde do Trabalhador no Brasil. Enfim, repensar esta questão, melhor analisá-la e estabelecer agendas propositivas de enfrentamento são os enormes desafios do SUS. Encerramos com as palavras do próprio García-Villegas (2013, P. 86):

\section{Referências}

ALMEIDA, M. Um olhar sobre a vigilância em saúde do trabalhador: a dinâmica entre o saber e o fazer no município do Rio de Janeiro. 2012. Dissertação (Mestrado em Saúde Pública) - Escola Nacional de Saúde Pública Sérgio Arouca, Fundação Oswaldo Cruz, Rio de Janeiro, 2012.

AMARAL, G. L.; OLENIKE, J. E.; AMARAL, L. M. F. (Coord.). Quantidade de Normas Editadas no Brasil: 25 anos da Constituição Federal de 1988. Curitiba: Instituto Brasileiro de Planejamento e Tributação, 2013.

BARROSO, L. R. Fundamentos Teóricos e Filosóficos do Novo Direito Constitucional Brasileiro. Revista da EMERJ, Rio de Janeiro, v. 4, n. 15, p. 11-48, 2001.

BRASIL. Ministério da Previdência Social. Anuário Estatístico da Previdência Social. 2011a. Disponível em: <http://www.previdencia.gov.br/arquivos/office/27_130924-151222-748.pdf >. Acesso em: 14 jan. 2015.

Decreto 7.508, de 28 de junho de 2011.

Regulamenta a Lei no 8.080, de 19 de setembro de 1990, para dispor sobre a organização do Sistema Único de Saúde - SUS, o planejamento da saúde, a assistência à saúde e a articulação interfederativa, e dá outras providências. Diário Oficial [da] União. Brasília, DF 2011b. Disponível em: <http://www.planalto.gov.br/ ccivil_03/_ato2011-2014/2011/decreto/D7508.htm>. Acesso em: 18 jan. 2015.

. Ministério da Previdência Social. AEPS 2013 Seção IV - Acidentes do Trabalho, 2013. Disponível em:
[...] al ver que la constitución no cumple con las promesas de cambio social, de justicia e igualdad que prometió, no sólo le quita su apoyo, sino que termina por convencerse de que ella es el fruto de una estrategia de engaño por parte de las élites dominantes. A su juicio, las constituciones aspiracionales, con su lenguaje generoso e incluyente, sirven más al poder para legitimar el statu quo que a los ciudadanos para proteger sus derechos.

$<$ http://www.previdencia.gov.br/aeps-2013-secao-iv-acidentes-do-trabalho/>. Acesso em: 14 jan. 2015a.

Ministério da Saúde. Secretaria de Gestão Estratégica e Participativa. Departamento de Articulação Interfederativa. Coordenação Geral de Articulação de Instrumentos da Gestão Interfederativa. Orientações acerca dos indicadores da pactuação de diretrizes, objetivos e metas 2012. Disponível em: $<$ http://portalweb04.saude.gov.br/sispacto/Instrutivo_ Indicadores_2012.pdf >. Acesso em: 18 jan. 2015b.

Supremo Tribunal Federal. Segunda turma ag: reg. No recurso extraordinário com agravo 639.337 São Paulo. 2011c. Disponível em: $<$ http://redir.stf.jus.br/paginadorpub/paginador. jsp? docTP=AC\&docID=627428 $>$. Acesso em: $16 \mathrm{dez}$. 2014.

CONSELHO NACIONAL DE SECRETÁRIOS DE SAÚDE (CONASS). A gestão da saúde nos estados: avaliação e fortalecimento das funções essenciais. Brasília, DF: CONASS, 2007.

DIAS, E. C. A atenção à saúde dos trabalhadores no setor saúde (SUS), no Brasil: realidade, fantasia ou utopia? 1994. 335 f. Tese (Doutorado em Saúde Coletiva) - Faculdade de Ciências Médicas, Campinas: Universidade Estadual de Campinas, 1994.

DIAS, E. C.; HOEFEL, M. G. O desafio de implementar as ações de saúde do trabalhador no SUS: a estratégia RENAST. Ciência \&t Saúde Coletiva, Rio de Janeiro, v. 10, n. 4, p. 817-828, 2005. 
DOBROWOLSKI, S. A inflação legislativa e a jurisdição constitucional. Revista da ESMESC, Santa Catarina, ano 5, v. 6, p. 253-267, maio 1999.

DUARTE, M. E. L. Análise do acidentes de trabalho causados por meio de transporte motocicleta em uma capital brasileira. 2011. Dissertação (Mestrado em Enfermagem) - Universidade Federal de Minas Gerais, Escola de Enfermagem, 2011.

FINKELMAN, J. (Org.). Caminhos da Saúde Pública no Brasil. Rio de Janeiro: Editora Fiocruz, 2002.

FLEURY, S. Reforma sanitária brasileira: dilemas entre o instituinte e o instituído. Ciência \&t Saúde Coletiva, Rio de Janeiro, v. 14, n. 3, jun. 2009.

GARCÍA-VILLEGAS, M. Constitucionalismo aspiracional. Araucaria. Revista Iberoamericana de Filosofía, Política y Humanidades, año 15, n. 29, p. 77-97, 2013.

KELSEN, H. O que é justiça?: a justiça, o direito e a política no espelho da ciência. 3 ed. São Paulo: Martins Fontes, 2001

LEÃO, L. H. C.; VASCONCELLOS, L. C. F. Rede nacional de atenção integral à saúde do trabalhador (Renast): uma rede que não enreda. In: VASCONCELLOS, L. C. F.; OLIVEIRA, M. H. B. (Org.). Saúde, trabalho e direito: uma trajetória crítica e a crítica de uma trajetória. Rio de Janeiro: Educam, 2011. p. 453-489.

LUHMANN, N. Sociologia do Direito II. Rio de Janeiro: Edições Tempo Brasileiro, 1985. 212 p. (Biblioteca Tempo Universitário; n. 80).
MARX, K. O capital: crítica da economia política. Livro I: Processo de Produção do Capital. 12 ed. Rio de Janeiro: Editora Bertrand Brasil, 1988.

OLIVEIRA, M. H. B.; VASCONCELLOS, L. C. F. Política de Saúde do Trabalhador no Brasil: muitas questões sem respostas. Cadernos de Saúde Pública, Rio de Janeiro, v. 8, n. 2, p. 150-156, 1992.

SCHMITZ, G. A. P. D. Omissões administrativas: hipóteses em que a omissão se torna ilegal. Âmbito Jurídico, Rio Grande, n. 115, ago. 2013. Disponível em: <http:// www.ambito-juridico.com.br/site/?n_link=revista_artigos_leitura\&artigo_id=13559>. Acesso em: 18 jan. 2015.

SOUZA, C. R. A inflação legislativa no contexto brasileiro. Revista da AGU - Advocacia-Geral da União, Brasília, DF, ano 11, n. 33, jul./set. 2012.

SPAGOLLA, V. S. M.; MORETE, V. S. A crise da lei e seus reflexos no direito administrativo: a legalidade questionada UNOPAR. Cient., Ciênc. Juríd. Empres., Londrina, v. 12, n. 2, p. 17-21, Set. 2011. Disponível em: $<$ http://revistas.unopar.br/index.php/juridicas/article/ view/1036>. Acesso em: 22 dez. 2014.

VASCONCELLOS, L. C. F. Saúde, trabalho e desenvolvimento sustentável: apontamentos para uma Política de Estado. 2007. 422 f. Tese (Doutorado em Saúde Pública) - Escola Nacional de Saúde Pública Sergio Arouca, Fundação Oswaldo Cruz, Rio de Janeiro, 2007.

Recebido para publicação em janeiro de 2015

Versão final em março de 2015

Conflito de interesse: inexistente

Suporte financeiro: não houve 